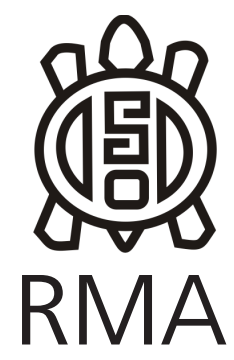

Editorial

\title{
Editorial. Homenaje a Patricia Escola en el 1 CAELA
}

\section{Editorial. Tribute to Patricia Escola at 1 Caela.}

\section{Cristina Bellelli*, María Teresa Civalero** y Gabriela Guraieb***}

* CONICET-Instituto Nacional de Antropología y Pensamiento Latinoamericano.

E-mail: crisbellelli@yahoo.com.ar

${ }^{*}$ CONICET-Instituto Nacional de Antropología y Pensamiento Latinoamericano,

Universidad de Buenos Aires. E-mail: mtcivalero@gmail.com

*** Instituto Nacional de Antropología y Pensamiento Latinoamericano.

E-mail: gabiguraieb@gmail.com

Cuando los editores del presente volumen nos contactaron no fue fácil aceptar la tarea quizás porque todavía, cuando ya ha pasado casi un año, nos conmociona y nos duele la ausencia de nuestra amiga y colega Patricia Escola. ¿Qué más podemos decir que no se haya dicho ya en todos los recordatorios que las diferentes revistas de nuestra especialidad le dedicaron? Releyéndolos nos queda claro el respeto que su trabajo creativo, dedicado y honesto despertó en la comunidad arqueológica y el afecto inmenso con que la recuerdan aquéllos a los que

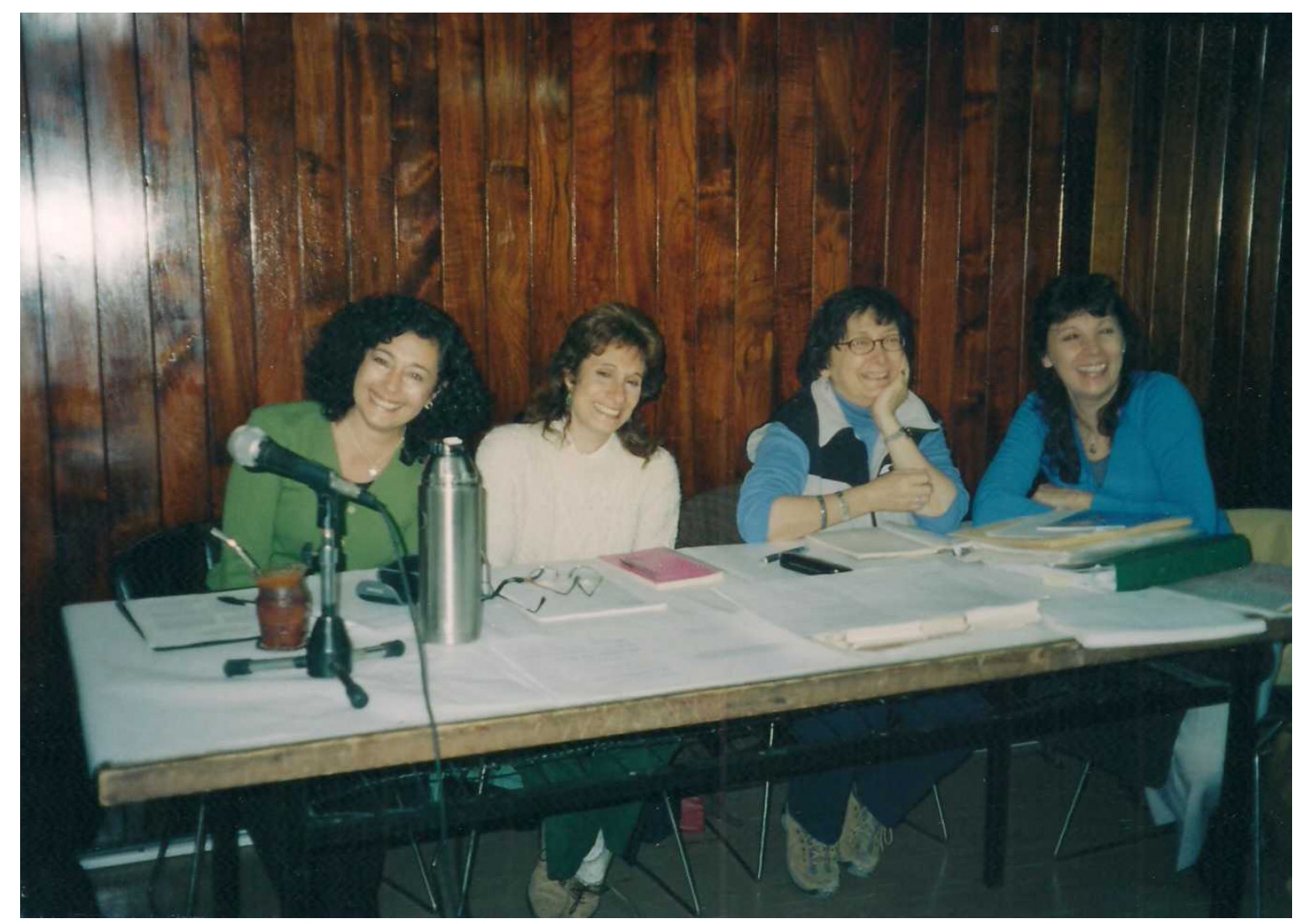

Figura 1. Segundo Taller Morfología macroscópica en la clasificación de artefactos líticos: Innovaciones y perspectivas. Horco Molle, Tucumán. 25 al 29 de Julio de 2005. De Izquierda a derecha: Gabriela Guraieb, Patricia Escola, Cristina Bellelli, María Teresa Civalero. Fotografía cedida por Salomón Hocsman.

Figure 1. Second Workshop Macroscopic morphology in the classification of lithic artifacts: Innovations and perspectives. Horco Molle, Tucumán. July 25 to 29, 2005. From left to right: Gabriela Guraieb, Patricia Escola, Cristina Bellelli, María Teresa Civalero. Photograph courtesy of Salomón Hocsman. 
guio en su devenir estudiantil y profesional. Si tenemos que resumir a Pato en pocas palabras, diríamos que gran parte de los eventos de su vida estuvieron signados por el amor. Amor a su pareja, Jorge Reales, que no soportó su ausencia y partió tras ella, a su hijo Julián a quien acompañamos como tías y tíos arqueólogos, a su profesión, a sus alumnas y alumnos. Amor a Antofagasta de la Sierra y su gente, el lugar al que le dedicó su vida profesional y al que volvió cuando ya no estaba, para descansar para siempre.

Amor y entrega nos deja Patricia de recuerdo y de enseñanza. Con ese mismo amor anidará en nuestros corazones. Y tu carcajada contagiosa, amiga, para no olvidarte nunca.

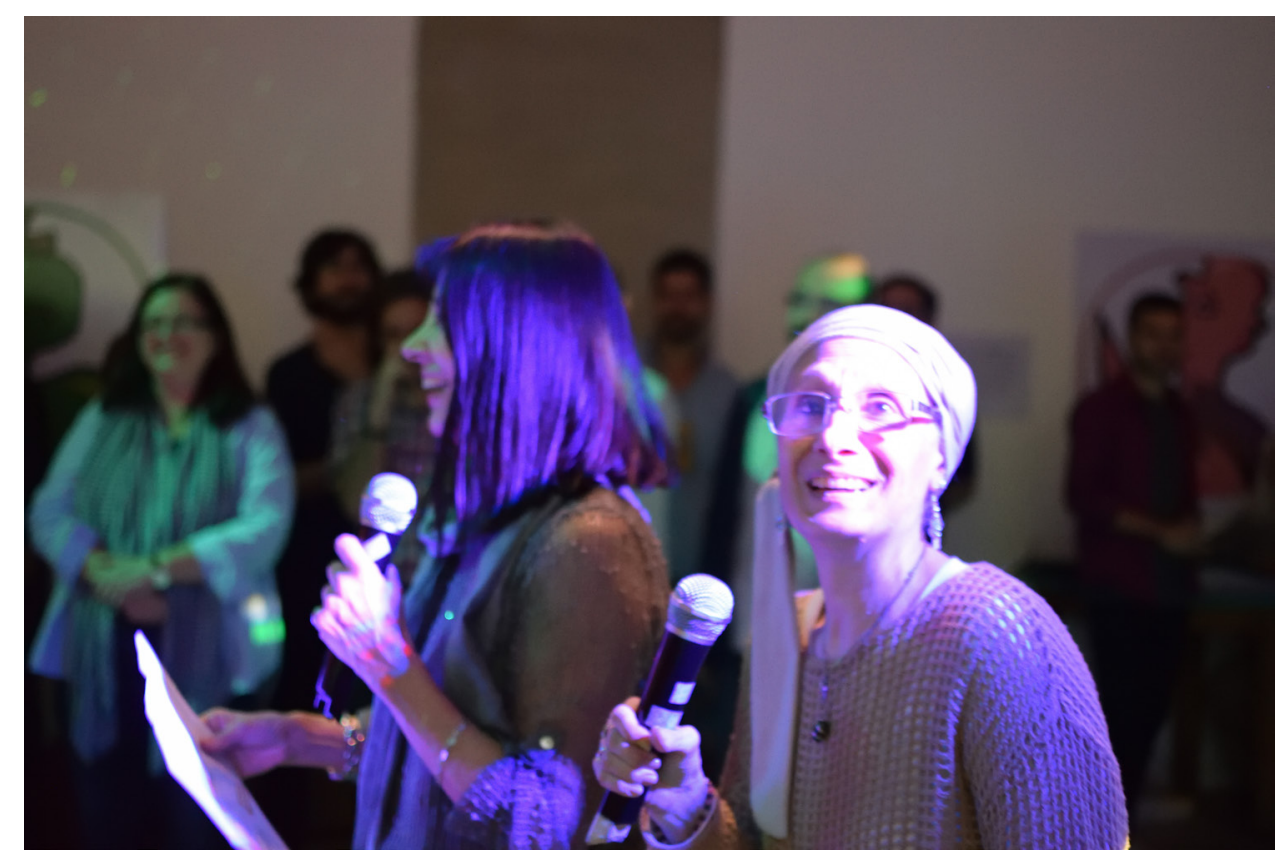

Figura 2. Homenaje a Patricia Escola en el 1 CAELA.

Figure 2. Tribute to Patricia Escola at 1 Caela. 